\title{
Os diferentes padrões morfológicos das Vilas de Itaipu'
}

\section{The different morphological patterns of Itaipu Villages}

\author{
Ramme, Juliana'; Pina, Silvia Mikami² \\ 1 Universidade Estadual de Campinas, julianaramme@gmail.com \\ 2 Universidade Estadual de Campinas, smikami@fec.unicamp.br
}

\begin{abstract}
RESUMO
Na década de 1970, Foz do Iguaçu (Brasil) iniciou um grande processo de expansão urbana impulsionado, sobretudo, pela implantação da Usina Hidrelétrica de Itaipu e de suas três vilas habitacionais: Vila A, Vila B e Vila C. Cada uma dessas vilas foi construída com diferentes padrões morfológicos, conforme as categorias de funcionários para quais elas foram destinadas, ou seja, a Vila A foi construída para os técnicos e funcionários administrativos, a Vila B foi construída para os diretores e gerentes da empresa e a Vila C para os operários da obra. Sendo assim, o objetivo deste artigo é analisar os projetos urbanísticos das Vilas de Itaipu a partir da identificação de seus padrões morfológicos. Para tanto, foi feito um levantamento de campo e análise de mapas, informações e plantas históricas, obtidos na Prefeitura Municipal de Foz do Iguaçu e no Acervo Técnico da ltaipu binacional. Os resultados apontam para clara distinção nos padrões morfológicos adotados para cada vila, impulsionando, com isso, fenômenos de segregação social e espacial. Espera-se que este estudo permita reconhecer a importância da morfologia urbana para compreensão da dinâmica tanto dos bairros habitacionais, quanto dos processos de expansão das cidades.
\end{abstract}

Palavras-chave: Padrões morfológicos; Habitação operária; Vilas de Itaipu.

\begin{abstract}
In the 1970s, Foz do Iguaçu (Brazil) started a great urban expansion process, driven mainly by the implementation of the Itaipu Hydroelectric Power Plant and its three housing villages: Vila A, Vila B and Vila C. Each one of these villages was constructed for different morphological patterns, according to the categories of employees for which they were intended, that is, Vila A was built for technicians and administrative staff, Vila B was built for the directors and managers of the company and Vila $C$ for the construction workers. Thus, the objective of this article is to analyze the urban planning projects of the Vilas de Itaipu from the identification of their morphological patterns. For this purpose, a field survey and analysis of maps, information and historical plans were carried out at the Municipality of Foz do Iguaçu and at the Itaipu Binacional Technical Collection. The results point to a clear distinction in the morphological patterns adopted for each village, impelling, with this, phenomena of social and spatial segregation. It is hoped that this study will allow us to recognize the importance of urban morphology for understanding the dynamics of housing districts as well as the expansion processes of cities.
\end{abstract}

\footnotetext{
${ }^{1}$ RAMME, Juliana; PINA, Silvia A. M. G. Os diferentes padrões morfológicos das Vilas de Itaipu. In: II SIMPÓSIO NACIONAL DE GESTÃO E ENGENHARIA URBANA: SINGEURB, 2019, São Paulo. Anais... Porto Alegre: ANTAC, 2019.
} 
Keywords: Morphological patterns, Company town, Itaipu Villages.

\section{INTRODUÇÃO}

O município de Foz do Iguaçu, no oeste do Paraná, se caracterizava como uma cidade de pequeno porte até a década 1970, com uma população de 33.966 habitantes. Entretanto, a construção da Itaipu Binacional, entre os anos de 1974 e 1984, fez com que a população do município desse um salto de $301 \%$ entre os anos de 1970 e 1980, devido ao grande contingente de trabalhadores que veio para a região em busca de uma vaga na usina. Segundo Souza (1998), no ano de 1978, a Itaipu Binacional contava com aproximadamente 40 mil funcionários.

Para abrigar parte dos seus trabalhadores, entre os anos de 1975 e 1977, foram construídos onze bairros habitacionais, sendo oito deles localizados no Paraguai e três no Brasil (Figura 1). As três Vilas de Itaipu implantadas em Foz do Iguaçu foram construídas com diferentes padrões morfológicos, conforme as categorias de funcionários para quais elas foram destinadas, gerando, com isso, diferentes impactos na paisagem urbana e nos processos de expansão futuros. Sendo assim, o objetivo deste artigo é analisar os projetos urbanísticos das Vilas de Itaipu a partir da identificação de seus padrões morfológicos.

Figura 1 - Mapa de localização das Vilas de Itaipu

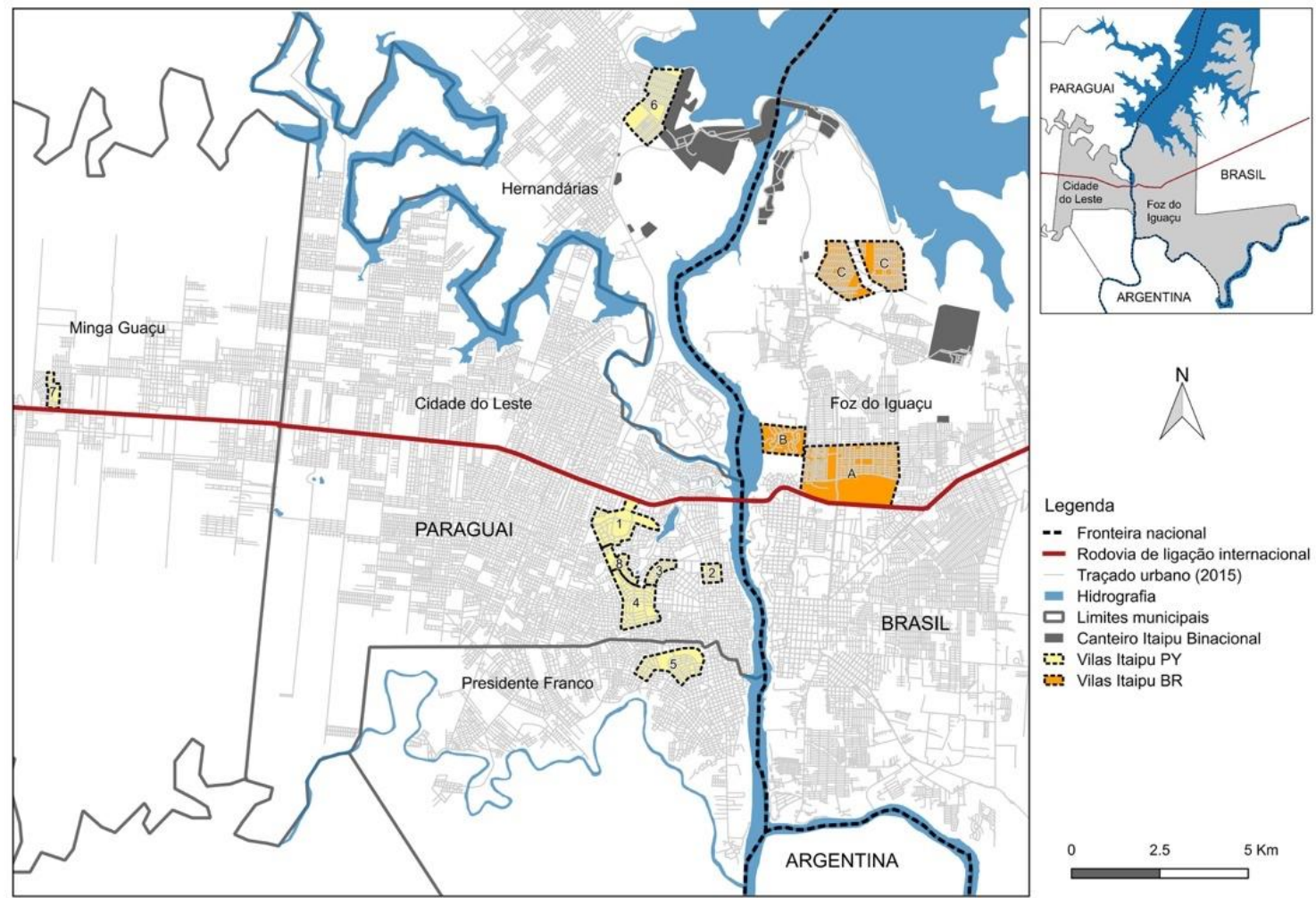

Fonte: As autoras, a partir da Prefeituras Municipais de Foz do Iguaçu (2017), Acervo Técnico Itaipu (2019), Araújo de Souza (2011) e Google Earth (2017).

Para isso, a metodologia utilizada vale-se de três etapas: (i) a primeira refere-se ao levantamento e mapeamento dos elementos morfológicos que compõe o plano urbano (ruas, parcelas e implantação dos edifícios); (II) a segunda etapa refere-se ao levantamento e análise dos tipos edilícios, que correspondem ao tecido edificado; e (iii) a terceira etapa analisa a relação entre o plano urbano e o tecido edificado, a fim de identificar os padrões morfológicos utilizados no projeto original das Vilas de Itaipu. Os dados analisados foram obtidos a partir da base cartográfica da Prefeitura Municipal de Foz do Iguaçu, do Acervo Técnico da Itaipu Binacional e do Google Earth. 


\section{A LEITURA DA PAISAGEM URBANA A PARTIR DOS PADRÕES MORFOLÓGICOS}

A cidade pode ser lida e compreendida a partir de diferentes perspectivas, sendo a Morfologia Urbana uma delas. Segundo Oliveira (2014), a Morfologia Urbana é a ciência que estuda a forma física da cidade, bem como os atores e os processos de transformação que a moldam. De acordo com Conzen (1960), a forma urbana está centrada na diversificação visível da paisagem urbana, formada a partir da ideia de uma divisão triparte, composta pelo plano, pelo tecido edificado e pelo uso do solo (Figura 2). A combinação desses três complexos resulta na configuração de diferentes padrões morfológico que, por sua vez, permitem compreender como e porque determinados processos tomam forma sobre o solo urbano ao longo dos anos.

Figura 2 - Divisão tripartite da paisagem urbana

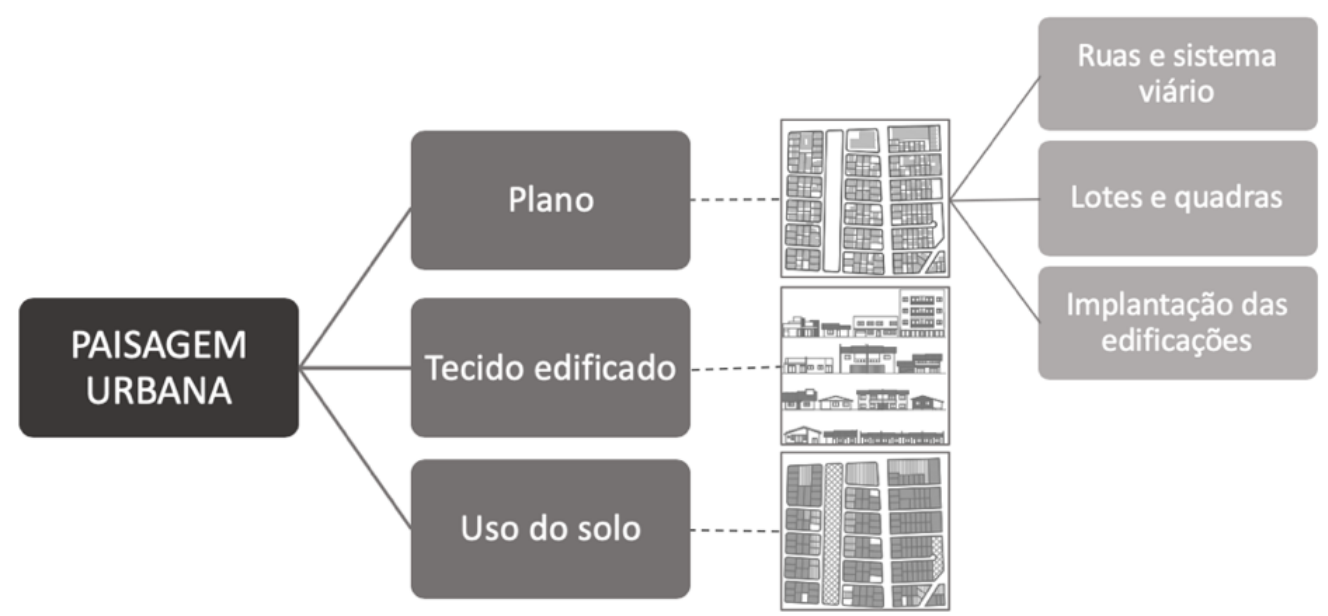

Fonte: As autoras, a partir de Conzen (1960)

Para Conzen (1960), o desenvolvimento das cidades em conjunto com a histórica cultural da região, está escrito no contorno e no tecido de suas áreas construídas. Para Whitehand (2009), um dos principais desafios que a Morfologia Urbana enfrenta atualmente é o fornecimento de bases sólidas para pesquisa comparativa e sua aplicação na prática de planejamento. Desta forma, é fundamental que o reconhecimento dos padrões morfológicos seja entendido em relação ao histórico da paisagem urbana, incluindo a tomada de decisão subjacente para uma perspectiva de pesquisa morfológica urbana mais ampla.

\section{A EXPANSÃO URBANA DE FOZ DO IGUAÇU A PARTIR DA IMPLANTAÇÃO DAS VILAS DE ITAIPU}

Até o ano de 1975, o município de Foz do lguaçu era composto pela área central e entorno da Ponte da Amizade (divisa com o Paraguai). Com a implantação da Itaipu Binacional e a construção de suas vilas habitacionais, este quadro se alterou significativamente. De acordo com Correia (2010), no Brasil, a implantação das vilas operárias promoveu alterações importantes na paisagem urbana e no modo de morar de milhares de pessoas. Valderrama e Oliveira (2008) afirmam que a construção dessas vilas foi pautada na segregação socioespacial, garantindo que a força de trabalho estivesse perto das empresas e permitindo uma maior capacidade de controle dos trabalhadores.

Seguindo essa dinâmica, as Vilas de Itaipu foram construídas segregadas da malha urbana existente, dividindo os funcionários de acordo com sua função dentro da empresa. A Vila $A$ foi destinada para os técnicos e funcionários administrativos, A Vila B foi para os diretores e gerentes e a Vila $C$ foi para os operários da obra. A localização das Vilas influenciou efetivamente nos processos de expansão futuros, pois apenas no entorno da Vila A novos bairros foram construídos, porém pouco influenciados pelo seu padrão morfológico. A Vila B teve seu projeto inserido estrategicamente no meio de amplas áreas verdes e do rio Paraná, mantendo-a isolada até hoje. Já a Vila $C$ teve seu crescimento limitado pelo canteiro de 
obras da Itaipu, pelo Lado da barragem e pelas linhas de transmissão, que acabaram isolando-a ainda mais e tornando inviável a expansão urbana no seu entorno (Figura 3).

Figura 3 - Localização das Vilas na malha urbana de Foz do Iguaçu

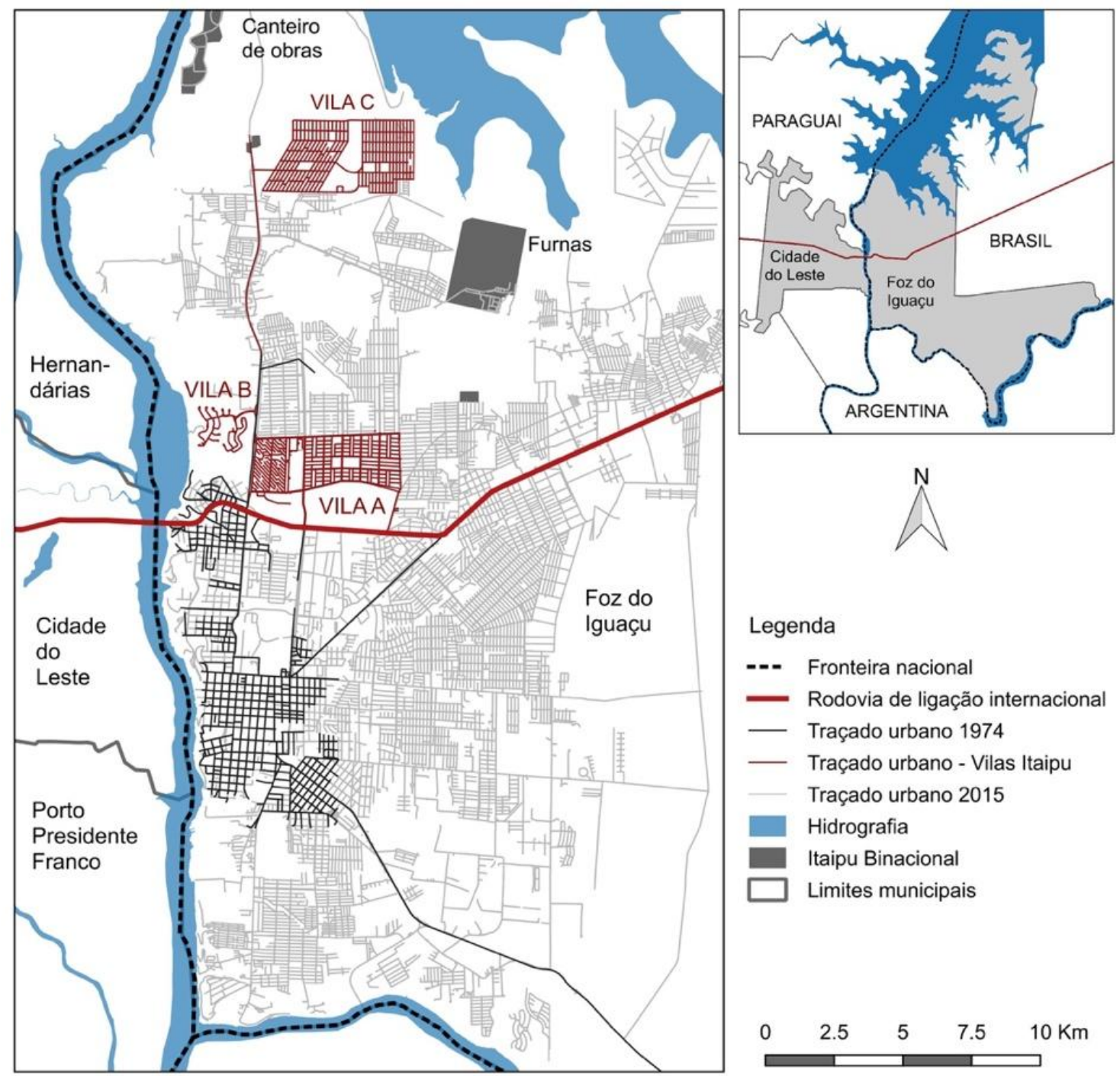

Fonte: As autoras, a partir da Prefeituras Municipais de Foz do Iguaçu, Acervo Técnico da Itaipu (2019)، Araújo de Souza (2011) e Google Earth (2015).

\section{OS PADRÕES MORFOLÓGICOS DAS VILAS DE ITAIPU}

A análise dos padrões morfológicos realiza-se a partir da análise dos três complexos da paisagem urbana: o plano, o tecido edificado e do uso do solo. Os dados analisados correspondem aos projetos arquitetônicos e urbanísticos originais, implantados entre os anos de 1975 e 1977. As Vilas apresentaram diferentes diretrizes urbanísticas para elaboração de seus projetos urbanísticos, assim como foram construídos 36 modelos de casas, divididos em 12 tipos (Quadro 1). Os tipos 1, 2 e 3 foram destinados para a Vila B, com áreas construídas que variavam de $150 \mathrm{~m}^{2}$ até $300 \mathrm{~m}^{2}$, implantados em todo loteamento. Os tipos 3 a 9 foram destinados para a Vila A, com áreas que variavam entre $68 \mathrm{~m}^{2}$ e $154 \mathrm{~m}^{2}$. Entretanto, sua localização foi dividida em quatro setores. Cabe ressaltar que o foco deste artigo é analisar os padrões morfológicos referentes às áreas residenciais, embora em todos as Vilas existam setores destinados para os equipamentos públicos e coletivos. Por fim, na Vila $C$ foi construído apenas uma tipologia de habitação, com metragens de $69 \mathrm{~m}^{2}$ e duas de $84 \mathrm{~m}^{2}$, pois o plano inicial era que fossem desmontadas após a obra da usina. 
Quadro 1 - Tipologia das edificações nas Vilas de Itaipu - Foz do Iguaçu

\begin{tabular}{|c|c|c|c|c|c|c|}
\hline \multirow{2}{*}{ Casa tipo } & \multicolumn{3}{|c|}{ Localização e quantidade } & \multirow{2}{*}{ Área média (m2) } & \multirow{2}{*}{ Variaçōes } & \multirow{2}{*}{$\begin{array}{l}\text { Padrão } \\
\text { construtivo }\end{array}$} \\
\hline & A & B & C & & & \\
\hline 1 & & 22 & & 275 até 299 & 4 & Superior \\
\hline 2 & & 52 & & 222 até 232 & 4 & Superior \\
\hline 3 & 17 & 147 & & 151 até 213 & 10 & Superior \\
\hline $3^{\prime}$ madeira & 214 & & & 150 e 154 & 2 & Bom \\
\hline 4 & 101 & & & 100 até 123 & 3 & Bom \\
\hline 4 madeira & 413 & & & 111 e 118 & 2 & Bom \\
\hline 5 & 136 & & & 88 ate 96 & 3 & Bom \\
\hline 6 & 397 & & & 80 & 2 & médio \\
\hline 7 & 390 & & & 68 & 2 & médio \\
\hline 8 & 225 & & & 80 & 1 & Popular \\
\hline 9 & 212 & & & 68 & 1 & Popular \\
\hline Geminadas & & & 2.900 & $69+84$ & & Popular \\
\hline Total & 2.105 & 221 & 2.900 & & & \\
\hline
\end{tabular}

Ao analisar a Vila A identificou-se quatro padrões morfológicos, que correspondem à quatro setores diferentes. Com relação ao plano, os três primeiros setores apresentam um traçado similar, composto por grandes avenidas de ligação e por vias de menor porte, que acessam apenas um grupo de quadras. Os lotes do setor 1 apresentaram área média de $1.000 \mathrm{~m}^{2}$, com uma taxa de ocupação de $25 \%$, a mesma encontrada na Vila B. Este setor é o único onde as casas foram construídas em madeira, com padrão considerado bom. Com relação aos lotes do setor 2, a área média era de $660 \mathrm{~m}^{2}$, com taxa de ocupação de 21\%. É possível identificar que em parte deles foi destinada uma ampla área frontal para ajardinamento, que coincide com uma das principais avenidas do bairro. Neste setor as edificações foram construídas em alvenaria, com um padrão construtivo considerado bom (Figura 4).

Com relação aos lotes do setor 3, a área média era de $530 \mathrm{~m}^{2}$, também com uma taxa de ocupação de $25 \%$. As edificações foram construídas em alvenaria com um padrão construtivo considerado bom. Por fim, o setor 4 se diferencia dos demais com relação ao plano. Apesar de ele também estar limitado por grandes avenidas, sua estrutura interna corresponde à pequenas vias tipo cul-de-sac, com corredores verdes e amplas áreas destinadas para ajardinamento no início das quadras. Os lotes apresentam formas e áreas variadas, não seguindo um padrão com relação à taxa de ocupação. Entretanto, as edificações apresentam em média $100 \mathrm{~m}^{2}$, com um padrão construtivo considerado popular (Figura 4). 
Figura 4 - Padrões morfológicos da Vila A por setor

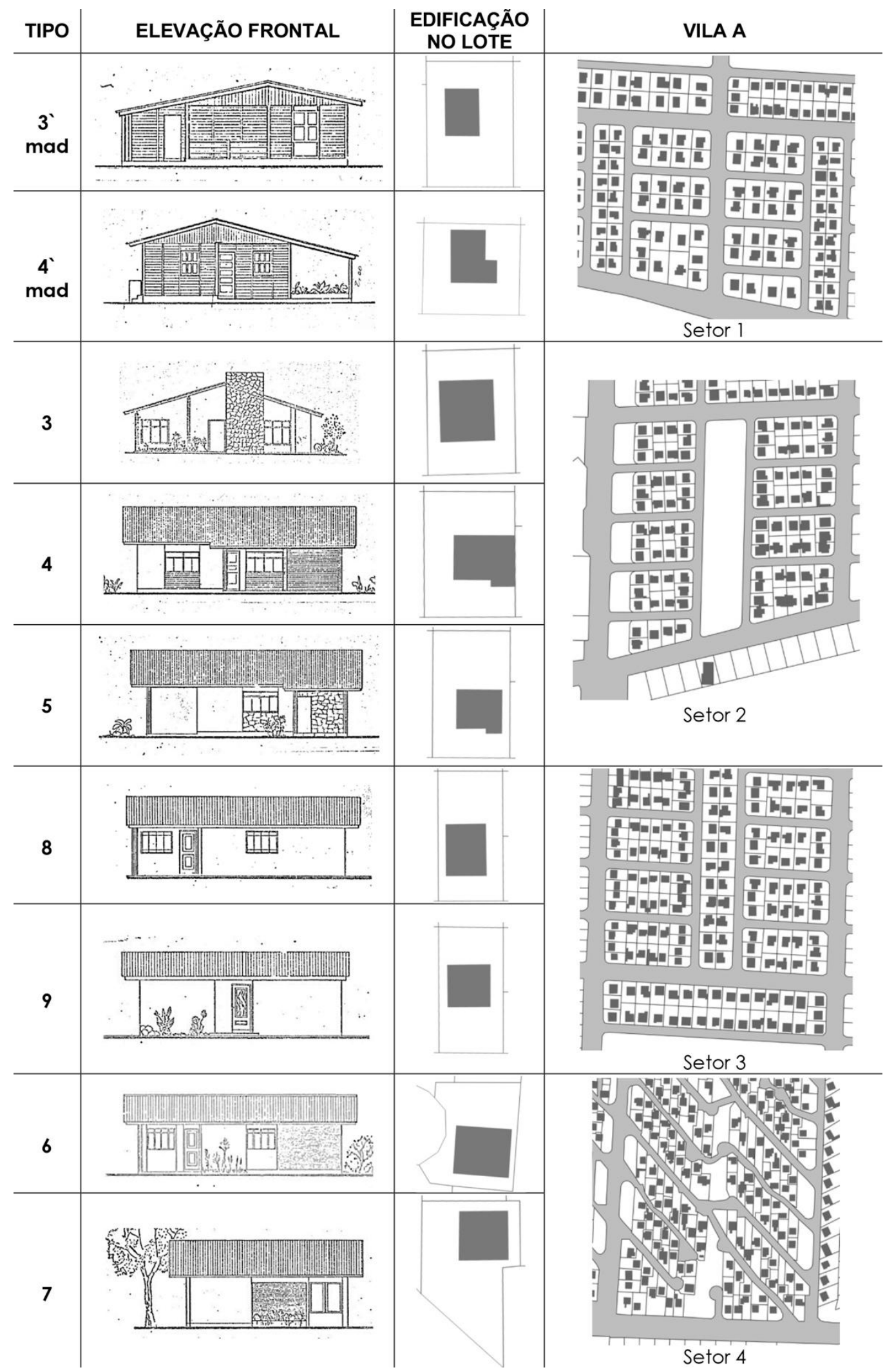

Fonte: As autoras, a partir de Itaipu Binacional (1986) e Prefeitura de Foz do Iguaçu (2017).

Ao analisar a Vila B, é possível identificar um padrão morfológico que corresponde às áreas habitacionais. Nele, o plano é composto por um traçado orgânico, com vias estreitas e amplos recuos de ajardinamento, sendo o formato dos lotes variável conforme o traçado 
viário e sua área de aproximadamente $1.200 \mathrm{~m}^{2}$ e taxa de ocupação média de $25 \%$. O tecido edificado era composto por casas de um pavimento, isoladas no lote e, embora as dimensões das plantas apresentem variações, todas foram construídas em alvenaria com um padrão construtivo considerado superior (Figura 5).

Figura 5 - Padrões morfológicos da Vila B

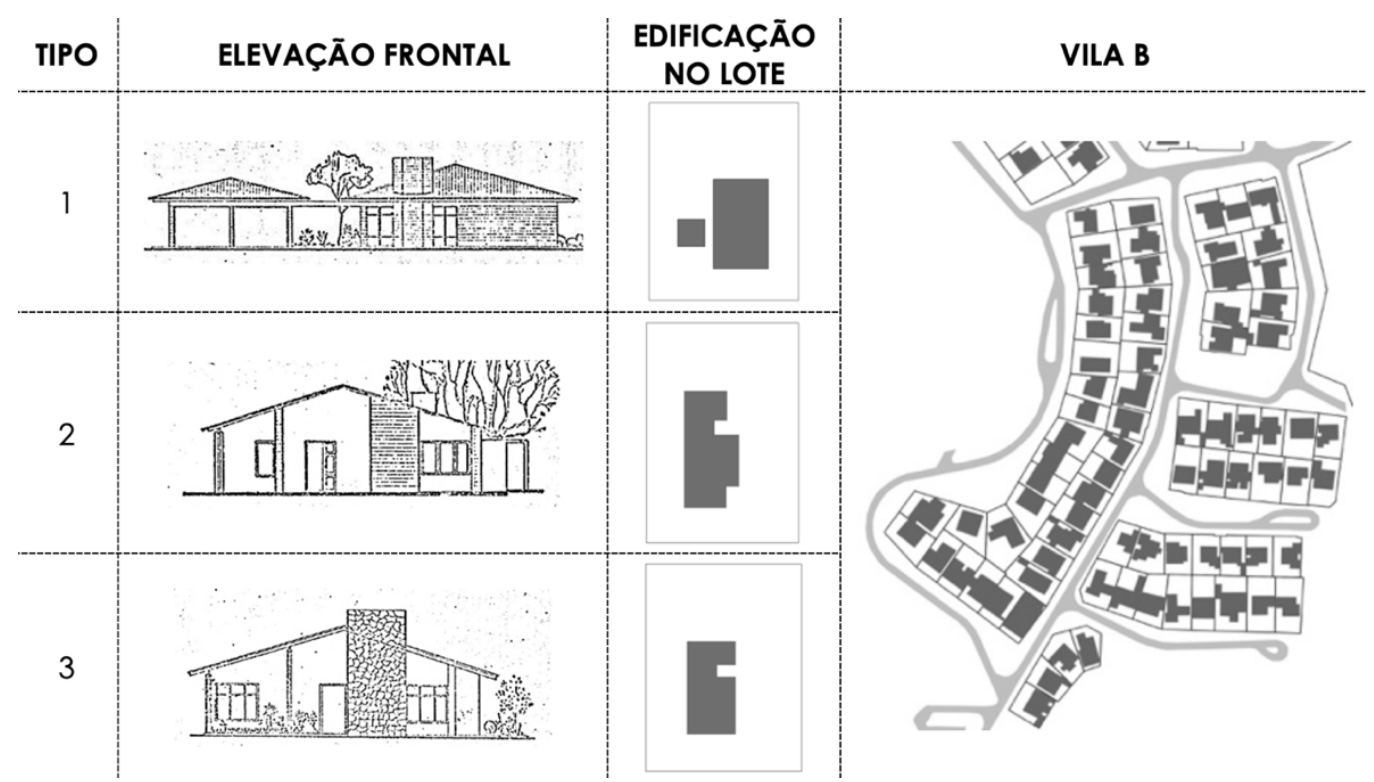

Fonte: As autoras, a partir de Itaipu Binacional (1986) e Prefeitura de Foz do Iguaçu (2017).

A Vila $C$, por sua vez, também apresentou apenas um padrão morfológico nas suas áreas residenciais, embora se diferencie muito daquele encontrado na Vila B. Nela, o plano era composto por um traçado ortogonal, com vias estreitas e lotes com área média de $504 \mathrm{~m}^{2}$, exceto aqueles localizados nas esquinas.

A forma dos lotes era predominantemente retangular e sua taxa de ocupação média era de 15\%. As edificações foram situadas no fundo dos lotes, de modo que a mesma estrutura de telhado cobrisse quatro unidades habitacionais. As edificações foram todas construídas em alvenaria, porém com um padrão considerado popular, ou seja, os materiais construtivos e os acabamentos empregados foram visivelmente inferiores às demais edificações implantadas nas demais vilas (Figura 6).

Figura 6 - Padrões morfológicos da Vila C

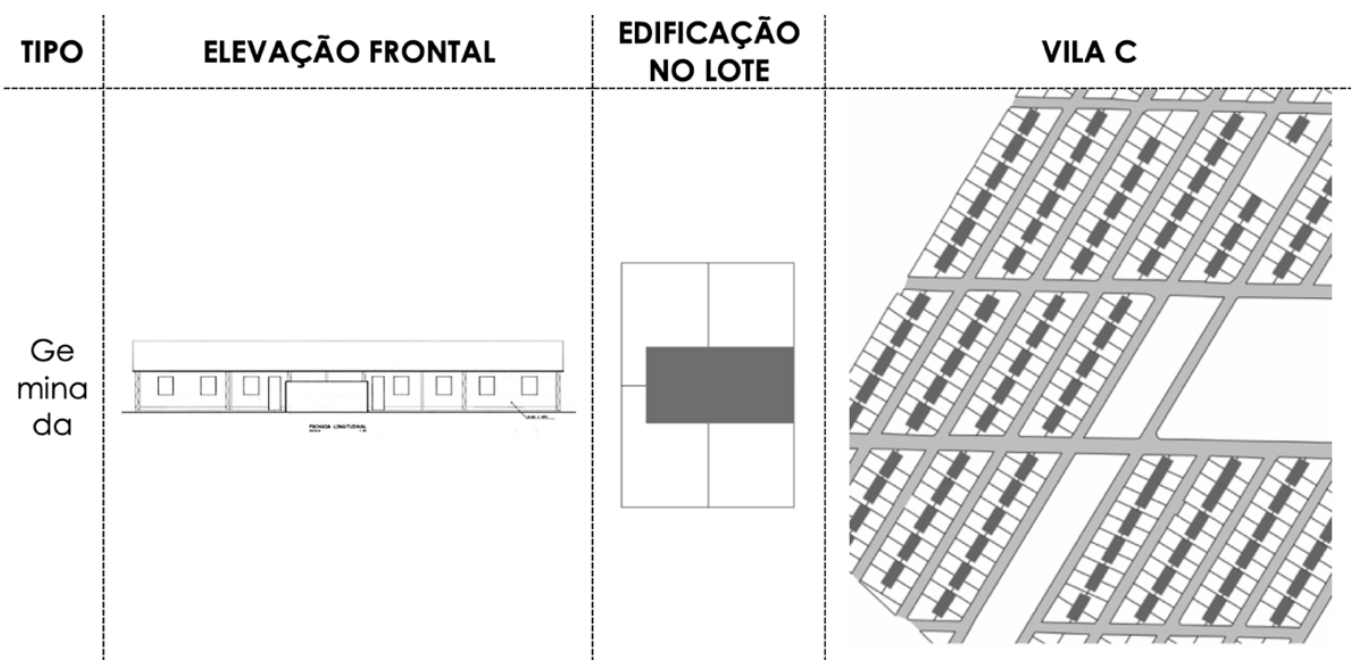

Fonte: As autoras, a partir de Acervo Técnico da Itaipu (2019) e Prefeitura de Foz do Iguaçu (2016). 


\section{CONSIDERAÇÕES FINAIS}

Da discussão desenvolvida neste artigo, depreende-se que a leitura morfológica da cidade abre novas perspectivas para a compreensão da paisagem urbana e possibilita novas abordagens para neutralizar ou corrigir rumos da dinâmica urbana.

A diferença no desenho urbano encontrado nas vilas em Foz do Iguaçu, devido aos seus padrões morfológicos, parece ter influenciado nos processos de expansão dos bairros vizinhos, embora com menor intensidade diante sua potência. Mesmo com a riqueza de padrões morfológicos da vila A, não houve sua assimilação nos bairros próximos pois a legislação urbanística desconsiderou tais possibilidades.

Para a vila $C$, que não foi desmontada como previsto, ainda predominam os padrões precários de urbanização e de isolamento urbano. Embora todos os terrenos apresentem grandes dimensões e suas taxas de ocupação não ultrapassem $30 \%$, a diferenciação com relação ao traçado e padrão construtivo utilizado aumentou ainda mais a segregação urbana e a diferenciação das áreas da cidade de acordo com a classe social de seus moradores, o que incentivou uma lógica perversa que tem reflexo, também, na construção de recentes territórios habitacionais.

\section{REFERÊNCIAS}

CONZEN, M. R. G. Alnwick, Northumberland: a study in town-plan analysis. London: Institute of British geographers, 1960.

CORREIA, T. B. Patrimônio Industrial e Agroindustrial no Brasil: a forma e a arquitetura dos conjuntos residenciais. In: SEGUNDO SEMINÁRIO DE PATRIMÔNIO AGROINDUSTRIAL, 2010, São Carlos. Anais Lugares de memória. São Carlos: SAP/EESC/USP, 2010. Disponível em:

<https://www.iau.usp.br/sspa/arquivos/palestras/Telma_de_Barros_Correia.pdf>. Acesso em: 25 de março. 2019.

ITAIPU BINACIONAL. Coletânea de plantas e fotos dos Conjuntos Habitacionais "A" e "B" da Itaipu Binacional. Arquivo Técnico da Itaipu Binacional, 1986.

OLIVEIRA, V. Diferentes abordagens no estudo da forma urbana. Revista de Morfologia Urbana, v. 2, n. 1, julho. 2014. ISSN 2182-7214. Disponível em: <https://pnum.fe.up.pt/engb/assets/pdf/rmu/rmu-2-1-editorial.pdf>. Acesso em: 07 de abril. 2018.

SOUZA, E. B. C. A Região do Lado de Itaipu: as políticas públicas a partir dos governos militares e a busca da construção de um espaço regional. 1998. 193 f. Dissertação (Mestrado) - Centro de Filosofia e Ciências Humanas, Universidade Federal de Santa Catarina, Florianópolis.

VALDERRAMA, B. B.; OLIVEIRA, M. R. S. Novos usos e significados das vilas operárias da antiga fábrica Brasital. Revista CPC, v.3, n. 5, abril. 2008. ISSN 1980-4466. Disponível em $<$ http://www.usp.br/cpc/v1/imagem/conteudo_revista_arti_arquivo_pdf/revista_cpc_05_patr imonio_cultural_04.pdf>. Acesso em: 26 de março. 2019.

WHITEHAND, J. W. R. The structure of urban landscapes: strengthening research and practice. Urban Morphology, v. 13, n. 1, 2009. ISSN 1027-4278. Disponível em: <http://www.urbanform.org/online_public/403.shtml>. Acesso em: 07 de abril. 2019. 